\title{
Transcriptome profiling of induced susceptibility effects on soybean-soybean aphid (Hemiptera: Aphididae) interaction
}

\author{
Surendra Neupane ${ }^{1}$, Adam J. Varenhorst ${ }^{2}$ and Madhav P. Nepal ${ }^{1 *}$ (1)
}

\begin{abstract}
Objectives: Soybean aphid (Aphis glycines Matsumura; SBA) is the most economically damaging insect of soybean (Glycine max) in the United States. One previous study demonstrated that avirulent (biotype 1) and virulent (biotype 2) biotypes could co-occur and interact on resistant (i.e., Rag 1) and susceptible soybean resulting in induced susceptibility after 11 days of feeding. The main objective of this research was to employ RNA sequencing (RNA-seq) technique to compare the induced susceptibility effect of biotype 2 on susceptible and resistant soybean at day 1 and day 11 (i.e., both susceptible and resistant soybean were initially challenged by biotype 2 and the effect was monitored through biotype 1 populations).

Data description: We investigated susceptible and Rag1 transcriptome response to SBA feeding in soybean plants colonized by biotype 1 in the presence or absence of an inducer population (i.e., biotype 2). Ten RNA datasets are reported with 266,535,654 sequence reads ( $55.2 \mathrm{~GB}$ ) obtained from pooled samples derived from the leaves collected at day 1 and day 11 post SBA infestation. A comprehensive understanding of these transcriptome data will enhance our understanding of interactions among soybean and two different biotypes of soybean aphids at the molecular level.
\end{abstract}

Keywords: Aphis glycines, Transcriptome, RNA-seq, Soybean, Induced susceptibility

\section{Objective}

Soybean aphid (Aphis glycines Matsumura; SBA) is the most economically damaging insect pest of soybean (Glycine $\max$ ) in the United States (US) [1]. In the US, it is estimated that annual economic losses due to the SBA are approximately $\$ 4$ billion [2]. Although host plant resistance to SBA exists, farmers rely on broad-spectrum foliar insecticide applications to reduce SBA populations [3]. The dependency on the use of chemical management has resulted in pyrethroid resistance in SBA populations in Iowa, Minnesota, North Dakota and South Dakota as well as the effects on non-target beneficial organisms [4, 5]. Host resistance to SBA is not widely adopted, which

\footnotetext{
*Correspondence: madhav.nepal@sdstate.edu

${ }^{1}$ Department of Biology and Microbiology, South Dakota State University, Brookings, SD 57007, USA

Full list of author information is available at the end of the article
}

may partially be due to the presence of four SBA biotypes (i.e., biotype 1: avirulent, biotype 2: virulent to Rag1, biotype 3: virulent to Rag2, biotype 4: virulent to Rag1, Rag2 and Rag1+Rag2) in the US [6-8]. Initial observations of SBA on resistant soybean were attributed to the presence of virulent biotypes [6-8]. However, Varenhorst et al. [6] demonstrated that inducer populations of avirulent (biotype 1) or virulent (biotype 2) biotypes improved conditions for subsequent (i.e., response) populations of biotype 1 or biotype 2 SBA on resistant (i.e., $\operatorname{Rag} 1$ ) and susceptible soybean, which is defined as induced susceptibility [9]. Furthermore, the induced susceptibility effect could be further categorized as feeding facilitation [10] (i.e., conspecific inducer improves host for conspecific response population) and obviation of resistance [11] (i.e., virulent inducer improves host susceptibility for avirulent response population). While induced susceptibility effects indicate that not all SBA observed 
Table 1 Overview of data files/data sets

\begin{tabular}{|c|c|c|c|}
\hline Label & Name of data file/data set & $\begin{array}{l}\text { File types (file } \\
\text { extension) }\end{array}$ & $\begin{array}{l}\text { Data repository and identifier (DOI } \\
\text { or accession number) }\end{array}$ \\
\hline Supplementary file 1 & Methodology description & Word document (.dox) & https://doi.org/10.6084/m9.figshare.7980176 \\
\hline Figure S1 & A flow chart representing experimental methods & Image file (.tiff) & https://doi.org/10.6084/m9.figshare.7980176 \\
\hline Figure S2 & A flow chart showing the RNA-seq data analysis pipeline & Image file (.tiff) & https://doi.org/10.6084/m9.figshare.7980176 \\
\hline Figure S3 & The hierarchical clustering of top 3000 variable genes & Image file (.tiff) & https://doi.org/10.6084/m9.figshare.7980176 \\
\hline Figure S4 & $\begin{array}{l}\text { The correlation between the samples using the top 75\% } \\
\text { genes }\end{array}$ & Image file (.tiff) & https://doi.org/10.6084/m9.figshare.7980176 \\
\hline Figure S5 & $\begin{array}{l}\text { Quality metrics of G. max sequencing data. (a) Mean } \\
\text { quality scores per position. (b) Per sequence quality } \\
\text { scores. (c) GC content distribution. (d) Read length } \\
\text { distribution }\end{array}$ & Image file (.tiff) & https://doi.org/10.6084/m9.figshare.7980176 \\
\hline Data file 1 & $\begin{array}{l}\text { Control: No aphids; Susceptible soybean; Day 1; SRR88 } \\
48027\end{array}$ & fastq file (.fastq) & https://identifiers.org/ncbi/insdc.sra:SRR8848027 \\
\hline Data file 2 & $\begin{array}{l}\text { Control: No aphids; Susceptible soybean; Day 11; SRR88 } \\
48028\end{array}$ & fastq file (.fastq) & https://identifiers.org/ncbi/insdc.sra:SRR8848028 \\
\hline Data file 3 & $\begin{array}{l}\text { Control: No aphids; Resistant soybean; Day 1; SRR88 } \\
48025\end{array}$ & fastq file (.fastq) & https://identifiers.org/ncbi/insdc.sra:SRR8848025 \\
\hline Data file 4 & $\begin{array}{l}\text { Control: No aphids; Resistant soybean; Day 11; SRR88 } \\
48026\end{array}$ & fastq file (.fastq) & https://identifiers.org/ncbi/insdc.sra:SRR8848026 \\
\hline Data file 5 & $\begin{array}{l}\text { Inducer: None; Response: } 15 \text { biotype 1; Susceptible } \\
\text { soybean; Day 11; SRR8848031 }\end{array}$ & fastq file (.fastq) & https://identifiers.org/ncbi/insdc.sra:SRR8848031 \\
\hline Data file 6 & $\begin{array}{l}\text { Inducer: } 50 \text { biotype 2; Response:15 biotype 1; Suscepti- } \\
\text { ble soybean; Day 1;SRR8848032 }\end{array}$ & fastq file (.fastq) & https://identifiers.org/ncbi/insdc.sra:SRR8848032 \\
\hline Data file 7 & $\begin{array}{l}\text { Inducer: } 50 \text { biotype 2; Response: } 15 \text { biotype1; Suscepti- } \\
\text { ble soybean; Day 11; SRR8848029 }\end{array}$ & fastq file (.fastq) & https://identifiers.org/ncbi/insdc.sra:SRR8848029 \\
\hline Data file 8 & $\begin{array}{l}\text { Inducer: None; Response: } 15 \text { biotype 1; Resistant soy- } \\
\text { bean; Day 11; SRR8848030 }\end{array}$ & fastq file (.fastq) & https://identifiers.org/ncbi/insdc.sra:SRR8848030 \\
\hline Data file 9 & $\begin{array}{l}\text { Inducer: } 50 \text { biotype 2; Response: } 15 \text { biotype 1; Resistant } \\
\text { soybean; Day 1; SRR8848023 }\end{array}$ & fastq file (.fastq) & https://identifiers.org/ncbi/insdc.sra:SRR8848023 \\
\hline Data file 10 & $\begin{array}{l}\text { Inducer: } 50 \text { biotype 2; Response: } 15 \text { biotype 1; Resistant } \\
\text { soybean; Day 11; SRR8848024 }\end{array}$ & fastq file (.fastq) & https://identifiers.org/ncbi/insdc.sra:SRR8848024 \\
\hline Data file 11 & $\begin{array}{l}\text { Control: No aphids; Susceptible soybean; Day 1; GSM37 } \\
17543\end{array}$ & txt (.txt.gz) & http://identifiers.org/geo:GSM3717543 \\
\hline Data file 12 & $\begin{array}{l}\text { Control: No aphids; Susceptible soybean; Day 11; GSM37 } \\
17544\end{array}$ & txt (.txt.gz) & http://identifiers.org/geo:GSM3717544 \\
\hline Data file 13 & $\begin{array}{l}\text { Control: No aphids; Resistant soybean; Day 1; GSM37 } \\
17545\end{array}$ & txt (.txt.gz) & http://identifiers.org/geo:GSM3717545 \\
\hline Data file 14 & $\begin{array}{l}\text { Control: No aphids; Resistant soybean; Day 11; GSM37 } \\
17546\end{array}$ & txt (.txt.gz) & http://identifiers.org/geo:GSM3717546 \\
\hline Data file 15 & $\begin{array}{l}\text { Inducer: None; Response: } 15 \text { biotype 1; Susceptible } \\
\text { soybean; Day 11; GSM3717547 }\end{array}$ & txt (.txt.gz) & http://identifiers.org/geo:GSM3717547 \\
\hline Data file 16 & $\begin{array}{l}\text { Inducer: } 50 \text { biotype 2; Response: } 15 \text { biotype 1; Suscepti- } \\
\text { ble soybean; Day 1; GSM3717548 }\end{array}$ & txt (.txt.gz) & http://identifiers.org/geo:GSM3717548 \\
\hline Data file 17 & $\begin{array}{l}\text { Inducer: } 50 \text { biotype 2; Response: } 15 \text { biotype1; Suscepti- } \\
\text { ble soybean; Day 11; GSM3717549 }\end{array}$ & txt (.txt.gz) & http://identifiers.org/geo:GSM3717549 \\
\hline Data file 18 & $\begin{array}{l}\text { Inducer: None; Response: } 15 \text { biotype 1; Resistant soy- } \\
\text { bean; Day 11; GSM3717550 }\end{array}$ & txt (.txt.gz) & http://identifiers.org/geo:GSM3717550 \\
\hline Data file 19 & $\begin{array}{l}\text { Inducer: } 50 \text { biotype 2; Response: } 15 \text { biotype 1; Resistant } \\
\text { soybean; Day 1; GSM3717551 }\end{array}$ & txt (.txt.gz) & http://identifiers.org/geo:GSM3717551 \\
\hline Data file 20 & $\begin{array}{l}\text { Inducer: } 50 \text { biotype 2; Response: } 15 \text { biotype 1; Resistant } \\
\text { soybean; Day 11; GSM3717552 }\end{array}$ & txt (.txt.gz) & http://identifiers.org/geo:GSM3717552 \\
\hline Data file 21 & $\begin{array}{l}\text { The transformed transcript abundance counts for all the } \\
\text { samples }\end{array}$ & Spreadsheet (.x|sx) & https://doi.org/10.6084/m9.figshare.7980176 \\
\hline Data file 22 & The hierarchical clustering of top 3000 variable genes & Spreadsheet (.x|sx) & https://doi.org/10.6084/m9.figshare.7980176 \\
\hline Table S1 & $\begin{array}{l}\text { Statistics of the transcriptomic data using RNA-seq } \\
\text { pipeline used in this study }\end{array}$ & Word document (.dox) & https://doi.org/10.6084/m9.figshare.7980176 \\
\hline
\end{tabular}

The supplementary materials (Supplementary file 1, Figure S1-S5, Data file 21, Data file 22, and Table S1) can be assessed openly on Figshare [19]. The raw RNA-seq data (.fastq files) are available for download on the SRA [20] and the raw transcript abundance counts (.txt.gz) are available on Gene Expression Omnibus (GEO) [21] 
on the resistant hosts are necessarily virulent [9], the mechanism of the induced susceptibility effects is yet to be characterized. Therefore, the major objective of this study was to use RNA sequencing (RNA-seq) to characterize induced susceptibility in soybean when a biotype 2 inducer is present.

\section{Data description}

\section{Plant material and aphid biotypes}

The data in this submission came from a greenhouse experiment using two genotypes of soybean (susceptible cultivar LD12-1583R, and resistant cultivar LD12-15813Ra with Rag1 gene), and two SBA populations (biotype 1-avirulent and biotype 2-virulent [6]). A detailed overview of the experiment is provided in Supplementary file 1 and Figure S1 (Table 1).

\section{RNA extraction, library preparation, and sequencing}

Leaf samples collected at day 1 and day 11 from resistant and susceptible cultivars (non-infested, infested with inducer biotype 2: response biotype 1 ) were used to isolate RNA using PureLink RNA mini kit (Invitrogen, USA). Isolated RNA was treated with TURBO ${ }^{\mathrm{TM}}$ DNase (Invitrogen, USA) to remove any DNA contamination, following the manufacturer's instructions. The RNA samples from three replicates were pooled in equimolar concentration, and RNA-seq libraries were sequenced on an Illumina NextSeq 500 at 75 cycles. Ten RNA libraries were prepared and sequenced with the sequencing depth ranging from 24,779,816 to 29,72,4913 reads (Data files 1-10; Table 1; Table S1).

\section{Quality control assessment}

Quality control of reads was assessed using FastQC program (version 0.11.3) [12]. The FastQC results were visualized using MultiQC v1.3 [13]. Low quality bases $(\mathrm{QC}$ value $<20)$ and adapters were removed by trimming using the program Trimmomatic (version 0.36) [14]. The coding sequences (Gmax: Gmax_275_Wm82.a2.v1. transcript_primaryTranscriptOnly.fa.gz) were obtained from the Phytozome database and aligned using Salmon ver.0.9.1 [15] accessed from Bioconda [16] (Data files 11-20). A flow chart showing the RNA-seq data analysis pipeline is shown in Figure S2. The downstream analyses were conducted using iDEP 0.82 [17]. Read quants were filtered with 0.5 counts per million $(\mathrm{CPM})$ in at least one sample. Quantified raw reads were transformed using regularized $\log$ (rlog), which is implemented in the DESeq 2 package [18] (Data file 21). The transformed data were subjected to exploratory data analysis such as hierarchical clustering (Figure S3; Data file 22) and the correlation between samples (Figure S4).

\section{Statistics of transcriptome data}

The FastQC analysis showed Phred quality scores per base for all samples higher than 30, and GC content ranged from 45 to $46 \%$ with a normal distribution (Figure S5, Table S1). After trimming, over 99\% of the reads were retained as the clean and good quality reads. Upon mapping these reads, we obtained high mapping rate ranging from 90.4 to $92.9 \%$. Among the mapped reads, $85.8 \%$ to $91.9 \%$ reads were uniquely mapped. After filtering with 0.5 counts per million (CPM) in at least one sample and rlog transformation, a total of 37,468 genes $(66.9 \%$ of original 55,983) were retained for transformation (Data file 21). The hierarchical clustering based on 3000 most variable genes, sample distances (Figure S3; Data file 22) indicated that sample clustering followed the time points of sample collection (i.e., Day 1 and Day 11). The correlation between the samples using the top $75 \%$ of genes showed in a range of $0.96-1$ (Figure S4).

\section{Limitations}

The quality filtering of downloadable raw fastq files is recommended before use. Kal's z-test [22] integrated with CLC Genomics Workbench (https://www.qiage nbioinformatics.com/) and analysis guided by the reference genes could be used to study the differential gene expression for pooled samples with no replications.

\section{Abbreviations \\ SBA: soybean aphids; RNA-seq: RNA sequencing; CPM: counts per million; Rag: resistance to Aphis glycines.}

\section{Acknowledgements}

We thank Philip Rozeboom for his assistance in greenhouse experiments.

\section{Authors' contributions}

SN carried out the experiments. AJV collected the plant and aphid biotypes. AJV and MPN conceived the project and contributed designing the experiments. SN analyzed the data. All authors contributed writing this manuscript. All authors read and approved the final manuscript.

\section{Funding}

Funding for the greenhouse experiments and RNA sequencing came partly from South Dakota Soybean Research and Promotion Council (SDSRPCSA1800238), and partly from the United States Department of Agriculture hatch projects (SD00H469-13 and SD00H659-18) to M.P.N. SN received graduate teaching/research assistantships from the Department of Biology \& Microbiology to support his PhD dissertation work (data analysis, interpretation and writing of the manuscript) at South Dakota State University.

\section{Availability of data materials}

The raw fastq files were submitted to the National Center for Biotechnology Information and are available with accession numbers accession (SRR8848023-SRR8848032) under Bioproject PRJNA530958 (Project ID SRP190833) (Data files 1-10; SRR8848023, SRR8848024, SRR8848025, SRR88 48026, SRR8848027, SRR8848028, SRR8848029, SRR8848030, SRR8848031, SRR8848032; SRP190833) [20]. The data could be retrieved using fastq-dump tool SRA toolkit (http://www.ncbi.nlm.nih.gov/sra). The file for raw transcript abundance counts for all the samples was deposited at the Gene Expression Omnibus (GEO) database, GSE129626 (Data files 11-20; GSM3717543, GSM37 
17544, GSM3717545, GSM3717546, GSM3717547, GSM3717548, GSM3717549 , GSM3717550, GSM3717551, GSM3717552; GSE129626) [21]. The supplementary materials (Supplementary File 1, Figure S1-S5, Data file 21, Data file 22 and Table S1) can be assessed openly on Figshare (https://doi.org/10.6084/ m9.figshare.7980176.v5) [19]. Please see Table 1 and reference list for details and links to the data.

\section{Ethics approval and consent to participate}

Not applicable.

\section{Consent to publish}

Not applicable.

\section{Competing interests}

The authors declare that they have no competing interests.

\section{Author details}

${ }^{1}$ Department of Biology and Microbiology, South Dakota State University, Brookings, SD 57007, USA. ${ }^{2}$ Department of Agronomy, Horticulture and Plant Science, South Dakota State University, Brookings, SD 57007, USA.

Received: 26 April 2019 Accepted: 5 June 2019

Published online: 10 June 2019

\section{References}

1. Hartman G, Domier L, Wax L, Helm C, Onstad D, Shaw J, Solter L, Voegtlin D, d'Arcy C, Gray M. Occurrence and distribution of Aphis glycines on soybeans in Illinois in 2000 and its potential control. Plant Health Progr. 2001:2(1):17. https://doi.org/10.1094/PHP-2001-0205-01-HN.

2. Hill C, Chirumamilla A, Hartman G. Resistance and virulence in the soybean-Aphis glycines interaction. Euphytica. 2012;186(3):635-46. https ://doi.org/10.1007/s10681-012-0695-z.

3. Ragsdale DW, Landis DA, Brodeur J, Heimpel GE, Desneux N. Ecology and management of the soybean aphid in North America. Annu Rev Entomol. 2011;56:375-99. https://doi.org/10.1146/annurev-ento-120709-144755.

4. Koch RL, Potter BD, Glogoza PA, Hodgson EW, Krupke CH, Tooker JF, DiFonzo CD, Michel AP, Tilmon KJ, Prochaska TJ, Knodel JJ, Wright RJ, Hunt TE, Jensen B, Varenhorst AJ, McCornack BP, Estes KA, Spencer JL. Biology and economics of recommendations for insecticide-based management of soybean aphid. Plant Health Progr. 2016;17(4):265-9. https://doi. org/10.1094/PHP-RV-16-0061.

5. Varenhorst AJ, O'Neal ME. The response of natural enemies to selective insecticides applied to soybean. Environ Entomol. 2012;41(6):1565-74. https://doi.org/10.1603/EN12068.

6. Kim K-S, Hill CB, Hartman GL, Mian M, Diers BW. Discovery of soybean aphid biotypes. Crop Sci. 2008;48(3):923-8. https://doi.org/10.2135/crops ci2007.08.0447.

7. Hill CB, Crull L, Herman TK, Voegtlin DJ, Hartman GL. A new soybean aphid (Hemiptera: Aphididae) biotype identified. J Econ Entomol. 2010;103(2):509-15. https://doi.org/10.1603/EC09179.

8. Alt J, Ryan-Mahmutagic M. Soybean aphid biotype 4 identified. Crop Sci. 2013;53(4):1491-5. https://doi.org/10.2135/cropsci2012.11.0672.
9. Varenhorst A, McCarville M, O'Neal M. An induced susceptibility response in soybean promotes avirulent Aphis glycines (Hemiptera: Aphididae) populations on resistant soybean. Environ Entomol. 2015;44(3):658-67. https://doi.org/10.1093/ee/nvv051.

10. Price PW, Denno RF, Eubanks MD, Finke DL, Kaplan I. Insect ecology: behavior, populations and communities. Cambridge: Cambridge University Press; 2011.

11. Baluch SD, Ohm HW, Shukle JT, Williams CE. Obviation of wheat resistance to the hessian Fly through systemic induced susceptibility. J Econ Entomol. 2012;105(2):642-50.

12. Andrews S. FastQC: a quality control tool for high throughput sequence data. 2010. https://www.bioinformatics.babraham.ac.uk/projects/fastq cl. Accessed 16 Nov 2018.

13. Ewels P, Magnusson M, Lundin S, Käller M. MultiQC: summarize analysis results for multiple tools and samples in a single report. Bioinformatics. 2016;32(19):3047-8. https://doi.org/10.1093/bioinformatics/btw354.

14. Bolger AM, Lohse M, Usadel B. Trimmomatic: a flexible trimmer for Illumina sequence data. Bioinformatics. 2014;30(15):2114-20. https://doi. org/10.1093/bioinformatics/btu170.

15. Patro R, Duggal G, Love MI, Irizarry RA, Kingsford C. Salmon provides fast and bias-aware quantification of transcript expression. Nat Methods. 2017;14(4):417. https://doi.org/10.1038/nmeth.4197.

16. Grüning B, Dale R, Sjödin A, Chapman BA, Rowe J, Tomkins-Tinch CH, Valieris R, Köster J, Bioconda T. Bioconda: sustainable and comprehensive software distribution for the life sciences. Nat Methods. 2018;15(7):475. https://doi.org/10.1038/s41592-018-0046-7.

17. Ge SX, Son EW, Yao R. iDEP: an integrated web application for differential expression and pathway analysis of RNA-Seq data. BMC Bioinf. 2018;19(1):534. https://doi.org/10.1186/s12859-018-2486-6.

18. Love MI, Huber W, Anders S. Moderated estimation of fold change and dispersion for RNA-seq data with DESeq2. Genome Biol Evol. 2014;15(12):550. https://doi.org/10.1186/s13059-014-0550-8.

19. Neupane S, Varenhorst AJ, Nepal MP. Supplementary files for transcriptome profiling of induced susceptibility effects on soybean-soybean aphid interaction. Figshare; 2019. https://doi.org/10.6084/m9.figsh are.7980176.v5

20. Neupane S, Varenhorst AJ, Nepal MP. Characterization of induced susceptibility effects on soybean-soybean aphid interactions. Sequence Read Archive. SRP190833. 2019. http://identifiers.org/ncbi/insdc.Sra:SRP190833.

21. Neupane S, Varenhorst AJ, Nepal MP. Characterization of induced susceptibility effects on soybean-soybean aphid interactions. Gene Expr Omnibus. GSE129626. 2019. http://identifiers.org/geo:GSE129626.

22. Kal AJ, van Zonneveld AJ, Benes V, van den Berg M, Koerkamp MG, Albermann K, Strack N, Ruijter JM, Richter A, Dujon B. Dynamics of gene expression revealed by comparison of serial analysis of gene expression transcript profiles from yeast grown on two different carbon sources. Mol Biol Cell. 1999;10(6):1859-72. https://doi.org/10.1091/mbc.10.6.1859.

\section{Publisher's Note}

Springer Nature remains neutral with regard to jurisdictional claims in published maps and institutional affiliations.

Ready to submit your research? Choose BMC and benefit from

- fast, convenient online submission

- thorough peer review by experienced researchers in your field

- rapid publication on acceptance

- support for research data, including large and complex data types

- gold Open Access which fosters wider collaboration and increased citations

- maximum visibility for your research: over 100M website views per year

At BMC, research is always in progress.

Learn more biomedcentral.com/submissions 